\title{
The Risk of Developing Type 2 Diabetes in Kyrgyz Population
}

\section{Marina S Moldobaeva, Anastasia V Vinogradova, Dinara I Isabaeva, Nurdin A Satarov and Artem A Elistratov*}

Department of Internal Medicine, Kyrgyz State Medical Academy, Bishkek, Kyrgyzstan

\begin{abstract}
Background: The assessment of risk factors for diabetes contributes to early detection and timely prevention of this disease. Chui province of Kyrgyzstan is considered as a region with increasing number of patients with type 2 diabetes (Type 2 DM).

Objective: To study the features of the risk of developing Type 2 DM in the Kyrgyz population- residents of Chui province of Kyrgyzstan.

Methods: 55 vulnerable families with low income (227 respondents of Kyrgyz- Asian ethnic group) which live in Chui region, the low altitude of mountain belt (500-1200 meters from sea level), were selected randomly to the study. A cross-sectional study was performed. The odds ratios (ORs) and confidence intervals $(\mathrm{Cl})$ were calculated. Stratification was carried out by age and sex: 18-39 years, 40-49 years, 50-59 years, over 60 years; 43 men and 184 women. The FINDRISK questionnaire was used to assess the risk of developing Type 2 DM within ten years.

Results: The high risk a $16.2 \%$ and moderate increased risk a $46.6 \%$ were detected in men, which was primarily associated with arterial hypertension $(\mathrm{AH})$ and insufficient consumption of vegetables and fruits. In women the high risk a $19.7 \%$ and a slightly increased risk a $39.6 \%$ were defined and were associated with abdominal obesity (AO) and with $\mathrm{AH}$. Men and women had increased levels of BMI, AO and $\mathrm{AH}$ in the group older age than 60 years.

Conclusion: The more significant and common risk factors (RF) for Type 2 DM in men is $A H(60.4 \%)$, and in women: AO (80\%). The prevalence of RF for Type 2 DM in the Kyrgyz in Chui region of Kyrgyzstan increases with age. In Kyrgyz Chui region dominated by a slightly increased risk of developing diabetes in the next 10 years: $46.6 \%$ in men, $39.6 \%$ in women and it increases with age. The risk of developing Type 2 diabetes in the Kyrgyz in the valleys is associated with abdominal obesity in women, and with hypertension in men. Slightly increased risk of developing in the next 10 years diabetes in the next 10 years is predominated in both men and women.
\end{abstract}

Keywords: Diabetes; Risk factors; Arterial hypertension; Visceral obesity; Obesity; Low altitude

\section{Background}

Kyrgyz (Asian population) live and work in all mountain belts [1]. Mountain conditions modify diseases course and their RF's including Type 2 DM [2-4]. According to the International Diabetes Federation, the number of people with diabetes worldwide reached 382 million people in 2013, and by 2035 will reach 592 million [1-3]. The risk factors assessment for diabetes contributes to its early detection and timely prevention. Chui region of Kyrgyzstan is one of the region where the prevalence of patients with Type 2 diabetes increased from 912.8 in 2007 to 1151.8 per 100 thousand population in 2012, Waist circumference (WC) is an important predictor of diabetes, coronary heart disease and mortality independently of traditional factors such as hypertension, blood glucose level and lipoprotein [4-7]. 60\% of patients with acute myocardial infarction have carbohydrate metabolism impairment [8]. DALY's criteria show that the leading RFs are the main contributors to $60 \%$ burden of disease [9].

The prevalence of diabetes in valleys associated with higher energy intake than those living in the mountains [10]. In the low mountains of Kyrgyzstan the AO is significantly higher in women than in men under the age of 55 years [11]. Bearing in mind the commonality of RF's for CVD, AH, DM and their close relationship and the fact that DM is currently the third leading cause of death after cardiovascular disease and cancer, the diabetes screening is justified $[12,13]$.

\section{Methods}

Randomization was based on a survey of 55 families (227 respondents) of Kyrgyz living in Chui region (500-1000 1200 m). A cross-sectional study with the calculation of odds ratios (ORs) and confidence intervals $(\mathrm{CI})$ was performed. Stratification carried out by age: 18-39 years, $40-49$ years, 50-59 years, over 60 years of age, and sex: 43 men and 184 women. Delineation of mountain belts is performed by using classification of Mirrahimov and Meimanaliev T.S. [1,14].

To assess the risk of developing Type $2 \mathrm{DM}$ we used a questionnaire FINDRISK, which estimates the risk of diabetes within the next 10 years [7]. Patients underwent a physical examination with measurement of anthropometric parameters (height, weight, waist circumference (WC), and blood pressure (BP) by using recommendation of ESC/ESH (2013). Search was conducted in the Cochrane Central Register of Control Trials.

\section{Results}

In Kyrgyzstan, the prevalence of DM patients is increased from 767.6 in 2007 to 1020.4 per 100 thousand of population in 2012 [15]. The number of complications of diabetes continues to rise steadily as well. $34.8 \%$ of male and $80 \%$ of women had elevated WC, indicating the relatively high prevalence of $\mathrm{AO}$ in the population. In the group of men $74.4 \%$ of them were engaged in physical activity for 30 minutes or more per day, $25.6 \%$ - less than 30 minutes per day, and in the group of women $77.1 \%$ and $22.9 \%$ respectively.

*Corresponding author: Artem A Elistratov, Department of Internal Medicine, Kyrgyz State Medical Academy, 720020, 92, Bishkek, Kyrgyzstan, Tel: +996312665066; E-mail: briwayart@gmail.com

Received October 06, 2014; Accepted April 23, 2015; Published April 27, 2015

Citation: Moldobaeva MS, Vinogradova AV, Isabaeva DI, Satarov NA, Elistratov AA (2015) The Risk of Developing Type 2 Diabetes in Kyrgyz Population.General Med 3 180. doi:10.4172/2327-5146.1000180

Copyright: ( 2015 Moldobaeva MS,et al This is an open-access article distributed under the terms of the Creative Commons Attribution License, which permits unrestricted use, distribution, and reproduction in any medium, provided the original author and source are credited. 
Daily insufficient consumption of fruits and vegetables is revealed a $53.5 \%$ in a group of men and a $41.8 \%$ in the group of women. Use of antihypertensive drugs as one of the main RF of Type $2 \mathrm{DM}$ is defined in men in $60.4 \%$ and $62.5 \%$ among women. Family history as risk factors of Type $2 \mathrm{DM}$ is found in $18.6 \%$ in men and in $9.2 \%$ among women (Table 1, Figures 1 and 2). The main RF's of DM among the surveyed population of Chui region are consistently distributed as follows: for male: $\mathrm{AH}$, inadequate intake of fruit and vegetables and $\mathrm{AO}$; for women: $\mathrm{AO}, \mathrm{AH}$ and subsequent irregular consumption of vegetables and fruits.

Stratification of risk of Type $2 \mathrm{DM}$ defined following ranges: in a group of men 18, 6\% had less than 7 points (lower risk of developing Type $2 \mathrm{DM}$ in the next 10 years), $46.6 \%$ had 7.11 points (slightly increased risk of developing Type $2 \mathrm{DM}$ ), 18.6\% had 12-14 points (average risk of developing Type $2 \mathrm{DM}$ ), 16.2\% had 15-20 points (high risk of developing Type $2 \mathrm{DM}$ ), and nobody had more than 20 points(very high risk of developing Type 2 DM) (Figure 3).

In the group of women $8.7 \%$ had less than 7 points, $39.6 \%$ had 11.7 points, $32 \%$ had $12-14$ points, $19.7 \%$ had $15-20$ points, and nobody had more than 20 points (Figure 4). In women, following RF's such as BMI, $\mathrm{AO}, \mathrm{AH}$ increased with age. These RF's were the highest in the group of women older than 60 years $(22.3 \%, 40.2 \%$, and $32.6 \%$ respectively). In men it was defined a trend towards an increasing of BMI, visceral obesity and hypertension with age. These RF's were high in the group of men over 60 years (13.9\%, 25.6\%, and 30.2\%, respectively) (Table 2 and Figures 5-7). Significant and common RF in men with Type $2 \mathrm{DM}$ in Chui region is AH (OR $1.125,95 \%$ CI $0.579-2.189$ ), in women is obesity $(\mathrm{OR}=0.517,95 \%$ CI $0.240-1.114)$ with predomination of abdominal obesity (70\%) (OR 0.175, 95\% CI 0.086-0.356).

\section{Discussion}

Bearing in mind that the indigenous people of Kyrgyzstan live and work at all mountain belts the physiological functions of the human body, course of diseases and their risk factors, including diabetes, have their own features. In our study high WC was prevalent in women: $80 \%$,

\begin{tabular}{|c|c|c|c|c|c|}
\hline & $\begin{array}{c}\text { WC (men } \\
\mathbf{> 1 0 2} \mathbf{~ c m} \\
\text { women } \\
\mathbf{> 8 8} \mathbf{~ c m}) \\
(\%)\end{array}$ & $\begin{array}{c}\text { The } \\
\text { physical } \\
\text { activity } \\
\text { not } \\
\text { regular } \\
\mathbf{( \% )}\end{array}$ & $\begin{array}{c}\text { The fruit, } \\
\text { vegetables } \\
\text { and brown } \\
\text { bread not } \\
\text { regular } \\
\mathbf{( \% )}\end{array}$ & $\begin{array}{c}\text { The } \\
\text { treatment by } \\
\text { medications } \\
\text { for high } \\
\text { blood } \\
\text { pressure } \\
\text { on a regular } \\
\text { basis (\%) }\end{array}$ & $\begin{array}{c}\text { The presence of } \\
\text { the members of } \\
\text { immediate family } \\
\text { with diabetes } \\
\text { (\%) }\end{array}$ \\
\hline Men & 34.8 & 25.6 & 53.5 & 60.4 & 18.6 \\
\hline Women & 79.8 & 22.9 & 41.8 & 62.5 & 9.2 \\
\hline
\end{tabular}

Table 1: The prevalence of RF for Type 2 DM in the Kyrgyz in Chui region of Kyrgyzstan.

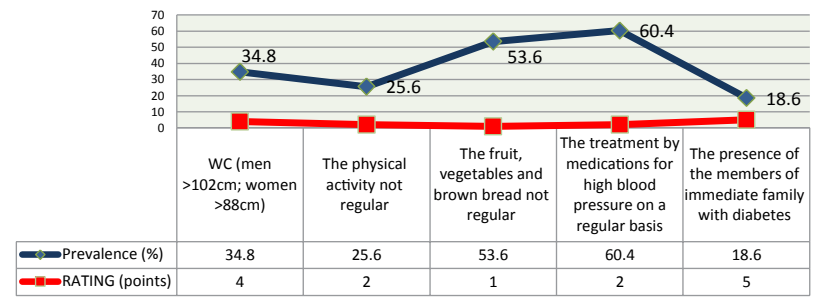

Figure 1: The structure of RF for Type 2 DM in the Kyrgyz men in Chui region of Kyrgyzstan.

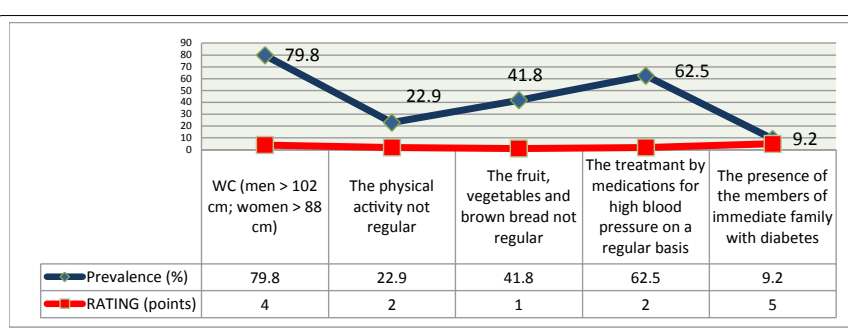

Figure 2: The structure of RF for Type 2 DM in the Kyrgyz women in Chui region of Kyrgyzstan.

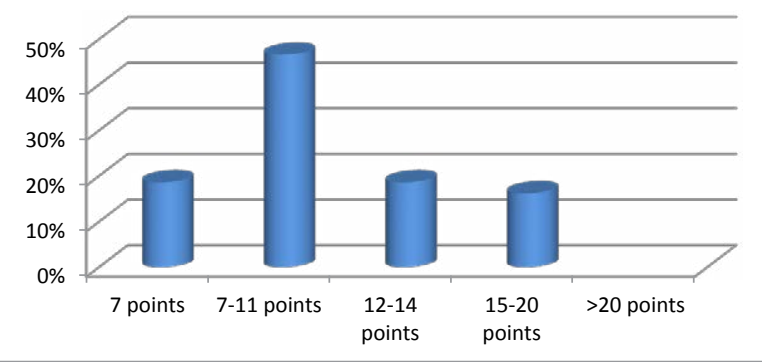

Figure 3: Stratification of risk of development of Type 2 DM in the Kyrgyz men in Chui region of Kyrgyzstan.

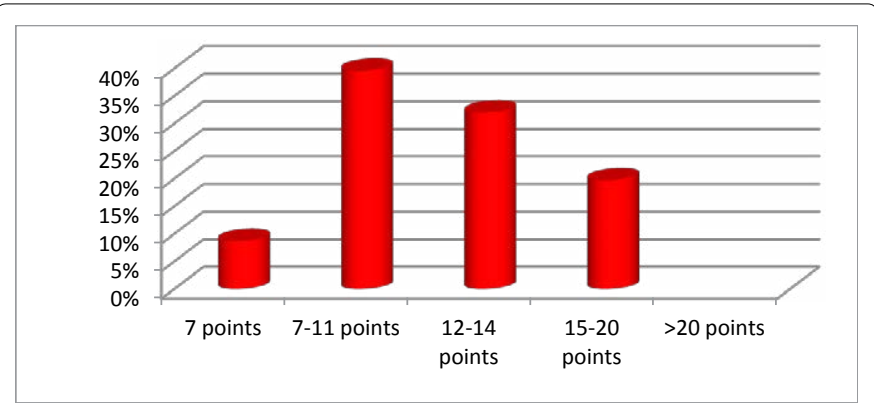

Figure 4: Stratification of risk of development of Type DM in the Kyrgyz women in Chui region of Kyrgyzstan.

\begin{tabular}{|c|c|c|c|c|c|c|c|c|}
\hline \multirow{2}{*}{$\begin{array}{l}\text { Age } \\
\text { Sex }\end{array}$} & \multicolumn{2}{|c|}{$18-39 y$} & \multicolumn{2}{|c|}{$40-49 y$} & \multicolumn{2}{|c|}{$50-59$ y } & \multicolumn{2}{|c|}{$>60$ yo } \\
\hline & m & $\mathbf{f}$ & m & $f$ & $\mathbf{m}$ & $\mathbf{f}$ & m & $\mathbf{f}$ \\
\hline $\mathrm{BM} \mid>30,0 \mathrm{~kg} / \mathrm{m}^{2}(\%)$ & 2.3 & - & 2.3 & 3.3 & 4.7 & 11.4 & 13.9 & 22.3 \\
\hline $\begin{array}{l}\text { WC }(\text { men }>102 \mathrm{~cm} ; \\
\text { women }>88 \mathrm{~cm})(\%)\end{array}$ & - & 2.7 & 2.3 & 10.9 & 9.3 & 23.4 & 25.6 & 40.2 \\
\hline $\begin{array}{c}\text { BO }>140 / 90 \mathrm{~mm} \\
\mathrm{Hg}(\%)\end{array}$ & 2.3 & 0.5 & 6.9 & 4.3 & 13.9 & 13.0 & 30.2 & 32.6 \\
\hline
\end{tabular}

Table 2: The prevalence of RF for Type 2 DM in the Kyrgyz in Chui region of Kyrgyzstan, depending on age and gender

than in men: $53.4 \%$, which coincides with the study of Mirrakhimov [15-18]: $73.7 \%$ and $35.5 \%$ respectively [11]. In other studies (Knyazev and Sultanalieva [19]) abdominal obesity was predominated in men (71.6\%) [16].

There were no significant differences in physical activity at least 30 minutes per day in groups of men (25.6\%) and women (22.9\%). In other studies [16] predominantly were women (51.7\%).

Daily insufficient consumption of fruits and vegetables is revealed $53.5 \%$ in a group of men and $41.8 \%$ in the group of women, which is 2 times more than results from other studies $(24.1 \%$ and $25 \%$, respectively) [16] . AH as a leading RF is predominated in men (60.4\%) and in women is predominated $\mathrm{AO}(80 \%)$ and both RF's increase with 


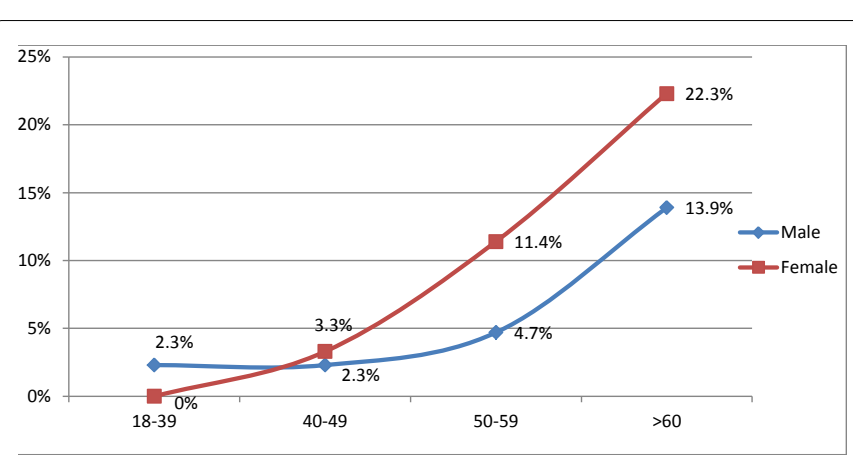

Figure 5: The prevalence of obesity $\left(\mathrm{BMl}>30.0 \mathrm{~kg} / \mathrm{m}^{2}\right)$ as risk factors for Type 2 diabetes, depending on age and gender.

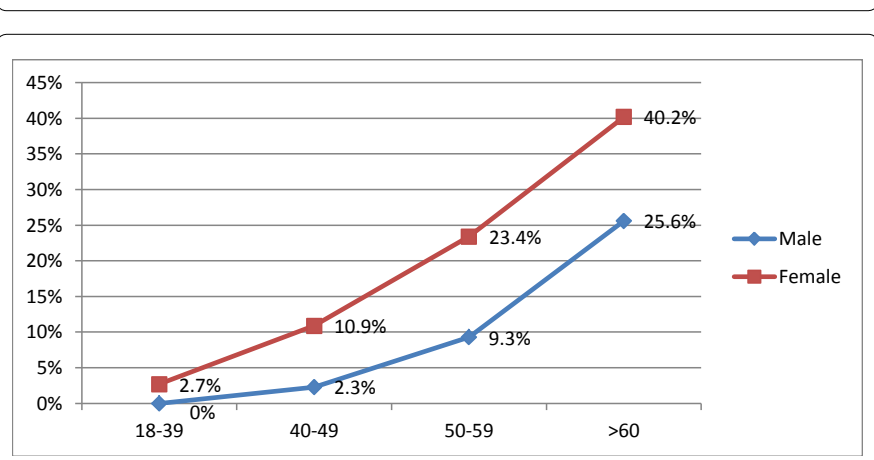

Figure 6: The prevalence of visceral obesity $(W C>102 \mathrm{~cm} />88 \mathrm{~cm})$ as risk factors for Type 2 diabetes, depending on age and gender.

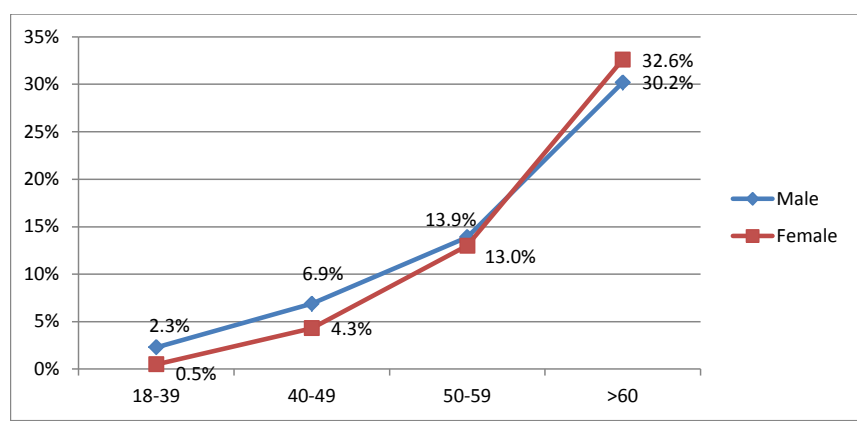

Figure 7: The prevalence of arterial hypertension $(>140 / 90 \mathrm{~mm} \mathrm{Hg})$ as risk factors for Type 2 diabetes, depending on age and gender.

age. Our findings are consistent with data from studies of Mirrakhimov [15] where $\mathrm{AH}$ was found in $57.9 \%$ of men, in $48.7 \%$ of women [11], with study of Abilova [20], where in 114 men of Kyrgyz nationality with metabolic syndrome $\mathrm{AH}$ was a leading RF, and with data from other studies (56.6\% and $496 \%$, respectively) [16].

In the Kyrgyz population with hypertension it is found the various disorders of lipid metabolism in $100 \%, 57.9 \%$ had a BMI over $30 \mathrm{~kg} /$ $\mathrm{m}^{2}, 35.4 \%$ carbohydrate metabolism impairment. In women with hypertension with metabolic syndrome the AO had a low specificity and it was its leading component [18]. Family history was detected in $18.6 \%$ in men and 9.2\% in women. Significant and common RF's in men with Type 2 DM in Chui region is AH (OR 1.125, 95\% CI 0.579-2.189), in women is obesity $(\mathrm{OR}=0.517,95 \% \mathrm{CI} 0.240-1.114)$ with predomination of $\mathrm{AO}$ (OR 0.175, 95\% CI 0.086-0.356), which increase by age.
Stratification of risk of Type $2 \mathrm{DM}$ identified following ranges: in a group of men $18,6 \%$ had lower risk of developing Type 2 DM in the next 10 years, $46.6 \%$ had a slightly increased risk, $18.6 \%$ had average risk, $16.2 \%$ had high risk, and nobody had very high risk. In the group of women: $8.7 \%$ had lower risk of developing Type $2 \mathrm{DM}$ in the next 10 years, $39.6 \%$ had a slightly increased risk, $32 \%$ had average risk, $19.7 \%$ had high risk, and nobody had very high risk.

The difference between men and women in the group of average risk, which are $18.6 \%$ and $32 \%$, can be explained by a combination of a higher frequency of AO in women (94\%), irregular consumption of vegetables and fruit (69\%), family history (18\%) in comparison with males $(75 \%, 45 \%, 10 \%)$. In Kyrgyzstan, $\mathrm{AH}$ and $\mathrm{AO}$ are more common in women (62.5\% and $80 \%$ respectively) and their frequency increases with age, so that is why a moderate risk of developing Type 2 DM among women is higher than in men.

The risk of developing Type $2 \mathrm{DM}$ in the Kyrgyz (Asian population) in Chui region has its own features. In men $\mathrm{AH}$ is the leading $\mathrm{RF}$ for diabetes, then inadequate intake of fruits and vegetables and $\mathrm{AO}$; in women the leading $\mathrm{RF}$ is $\mathrm{AO}$, then $\mathrm{AH}$, and irregular consumption of vegetables and fruits. Prevalence of RF for Type 2 DM in the Kyrgyz in Chui region of Kyrgyzstan increases with age. Stratification the risk of Type $2 \mathrm{DM}$ in both men and women showed prevalence of slightly increased risk. Studies [19-22] showed that the risks of developing Type $2 \mathrm{DM}$ in men increase with increasing cardiovascular risk: patients with a very high risk for CV risk according to SCORE scale also has a high and very high risk of developing Type 2 DM according to FINDRISC.

\section{Conclusions}

Significant and common RF for type 2 diabetes in men (60.4\%) is hypertension; in women is visceral obesity (80\%). Prevalence of RF for Type $2 \mathrm{DM}$ in the Kyrgyz in Chui region of Kyrgyzstan increases with age. In men $\mathrm{AH}$ is the leading $\mathrm{RF}$ for diabetes, then inadequate intake of fruits and vegetables and $\mathrm{AO}$; in women the leading RF is $\mathrm{AO}$, then $\mathrm{AH}$, and irregular consumption of vegetables and fruits. Stratification the risk of Type $2 \mathrm{DM}$ in both men and women showed prevalence of slightly increased risk of developing diabetes in the next 10 years: in men: $46.6 \%$, in women: $39.6 \%$, which increase with age.

\section{References}

1. Mirrahimov M, Meimanaliev T (1984) Mountain cardiology: Essays. 316

2. Moldobaeva M (1993) Distribution features, clinical and functional manifestations, prevention and treatment of obesity and diabetes mellitus 2 type the residents of Niagara (760-1200 m) and highland (2040-3500 m ). Abstract of dissertation 29.

3. Esenamanova M (1979) The Kyrgyz Health Care 6: 17-21

4. Djailobaev R, Greenstein B, Dubinin J, Narbekov O (1973) Physiology and pathology of the organism in the conditions of high mountains. 155-165.

5. Shestakova M (2009) Metabolic syndrome - a real threat to public health all over the world. J Med Vestnik 15 (484): 15-21.

6. International Diabetes Federation (2011) IDF Diabetes Atlas, (5thedn)

7. WHO (2008) 2008-2013 Action plan for the global strategy for the prevention and control of non communicable diseases.

8. World Health Organization (2000) Obesity: Preventing and Managing the Global Epidemic: Reporting WHO Consultation Geneva. World Health Organ Tech Rep Ser 894: i-xii, 1-253.

9. Butrova S, Dzgoeva F (2004) Visceral obesity - a key element of the metabolic syndrome. J Obesity and Metabolism 1:10-16.

10. Ismailov S, Berdykulova D, Haidarova $F(2010)$ The prevalence of late complications of diabetes mellitus in the regions of the Republic of Uzbekistan. 
Citation: Moldobaeva MS, Vinogradova AV, Isabaeva DI, Satarov NA, Elistratov AA (2015) The Risk of Developing Type 2 Diabetes in Kyrgyz Population. General Med 3: 180. doi:10.4172/2327-5146.1000180

Int $\mathrm{J}$ of Edocrinology 1: 34-39.

11. Castelli W, Anderson K (1986) A population at risk. Prevalence of high cholesterol levels in hypertensive patients in the Framingam study. Am J Med 80: 23-32.

12. Hara K, Matsushita Y, Horikoshi M (2006) A proposal for the cutoff point of waist circumference for the diagnosis of metabolic syndrome in the Japanese population. Diabetes Care 29: 1123-1134.

13. Wang Y, Rimm E, Stampfer M, Willett W, Hu F (2005) Comparison of abdominal adiposity and over all obesity in predicting risk of type 2 diabetes among men. Am J Clin Nutr 81: 555-563.

14. Anvarova ShS (2003) The prevalence and clinical and biochemical characteristics of diabetes in the population living in various climatic and geographical regions of Tajikistan. 50 .

15. Mirrakhimov E (2013) Prevalence of obesity and cardiovascular risk factors in the population of low, moderate and high altitude regions of Kyrgyzstan (preliminary results). J Clin Exp Cardiolog 4:4.

16. Bartnik M (2004) The prevalence of abnormal glucose regulation in patients with coronary artery disease across Europe. The Euro Heart Survey on diabetes and the heart. Eur Heart J 25: 1880-1890.
17. James W (2003) Overweight and Obesity. In Comparative Quantification of Health Risks: Global and Regional Burden of Disease Attributable et Selected Major Risk Factors.

18. Republican Medical Information Center (2011) Public health activities and health care organizations in the Kyrgyz Republic in 2010. 319.

19. KnyazevaV, Sultanalieva RB (2014) Prevalence of disorders of carbohydrate metabolism among residents of Chui and Naryn regions of Kyrgyzstan.

20. Abilova CC (2010) Clinical and functional features of the metabolic syndrome in the course of the two ethnic groups (Kyrgyz, Russian) depending on the number of its components. Abstract of dissertation 24.

21. Romanova TA (2011) Prevalence of the metabolic syndrome and its components in patients with essential hypertension with an estimate of their role in the development of cardiac, vascular and cerebral complications of the disease. Abstract of dissertation 46.

22. Kovrigina MN, Mammadov MN (2012) Evaluation of the risk of diabetes in men with different levels of cardiovascular risk. Rational Pharmacotherapy in Cardiology 8: 766-771. 